\title{
SOBRE EL PROGRAMA "JUSTICIA EN LENGUAJE CLARO" DEL MINISTERIO DE JUSTICIA Y DERECHOS HUMANOS DE LA NACIÓN (ARGENTINA)
}

\author{
DANIELA LAURIA ${ }^{1}$
}

\author{
Instituto de Lingüística, Facultad de Filosofía y Letras \\ Universidad de Buenos Aires / CONICET, República Argentina
}

danielalauria76@gmail.com

\begin{abstract}
Resumen. En 2017, se conformó una Red Nacional de Lenguaje Claro en la que participan representantes de los tres poderes del Estado. Las directrices del proyecto señalan que la claridad de las comunicaciones emitidas por el Estado colabora en el adecuado ejercicio de los derechos y de los deberes a la vez que fortalece la democracia, la transparencia, la confianza y la inclusión social. En este trabajo, se examina el programa "Justicia en lenguaje claro" del Ministerio de Justicia y Derechos Humanos con el objetivo de explicar sus implicancias glotopolíticas. Partimos de la idea de que se adopta esta medida de arbitrar el orden lingüístico con la (supuesta) voluntad de "empoderar a los ciudadanos", es decir, de transformar la distribución social del capital simbólico en el plano del lenguaje. Empero, los resultados muestran que esta campaña entraña una fuerte dimensión económica además de buscar controlar el orden social establecido.
\end{abstract}

Palabras clave: lenguaje claro; discurso jurídico; Estado; Argentina; Glotopolitica.

\begin{abstract}
In 2017, a National Network of Clear Language was formed in which representatives of the three branches of the State participate. The guidelines of the project indicate that the clarity of the communications issued by the State collaborates in the proper exercise of rights and duties while strengthening democracy, transparency, trust and social inclusion. In this paper, the program "Justice in plain language" of the Ministry of Justice and Human Rights is examined with the aim of explaining its glotopolitical implications. We start from the idea that this measure is adopted to arbitrate the linguistic order with the (supposed) will to "empower the citizens", that is, to transform the social distribution of symbolic capital in the field of language. However, the results show that this campaign involves a strong economic dimension as well as seeking to control the established social order.
\end{abstract} Keywords: clear language; legal discourse; State; Argentina; Glottopolitics.

\footnotetext{
${ }^{1}$ Doutora em Linguística pela Universidad de Buenos Aires, onde atua como docente e pesquisadora adjunta (CONICET).
} 


\section{INTRODUCCIÓN}

Históricamente, las extensas tradiciones de la retórica y de las artes de escribir se han especializado en la regulación de la discursividad estableciendo normativas para la producción de los discursos públicos legítimos en distintos ámbitos sociales significativos en cada etapa. Esas intervenciones han servido a determinados intereses y subjetividades en el marco de las condiciones políticas y socioeconómicas que prevalecen en cada coyuntura.

En la actualidad, la tendencia a la uniformización lingüística y discursiva -necesaria para el funcionamiento de los medios electrónicos y digitales de modo tal que faciliten la acción de los buscadores y de otras herramientas informáticas como los traductores automáticos o los chatbots-, la creencia en el poder de la palabra para "democratizar" las relaciones sociales y/o para manipular a los ciudadanos, y el control de la prestación rápida, eficiente y rentable (en el sentido de ahorrar costos y tiempos $\mathrm{y}$, con ello, aumentar la productividad) de los servicios ampliaron el alcance de dispositivos normativos capaces de afrontar la diversidad constitutiva de las sociedades contemporáneas, que consisten tanto en la imposición de reglas explícitas como de prácticas altamente normativizadas.

En términos de Auroux (1992), en el momento presente se está atravesando una nueva revolución tecno-lingüística. La primera corresponde a la invención de la escritura, que fue uno de los factores necesarios para la aparición de la reflexión sobre el lenguaje. La segunda, acompañada por, entre otros factores, la invención de la imprenta, fue el proceso de gramatización, que implicó una profunda transformación de la ecología de la comunicación a través de la creación de dos artefactos tecnológicos denominados "instrumentos lingüísticos" que construyen y fijan la lengua a partir de la formulación de normas y reglas como son la gramática y el diccionario monolingüe. La tercera y actual se relaciona, además de con los cambios socioeconómicos derivados de la globalización, con la mecanización y automatización del lenguaje: el desarrollo de las tecnologías de la palabra implanta ciertos formatos y modifica una vez más las representaciones y las prácticas en torno al modo de comunicación.

Si bien el tema de la regulación discursiva ha sido ampliamente estudiado tanto desde una perspectiva histórica (examen de retóricas y artes de escribir de diferentes épocas) como actual (examen de manuales de estilo para escribir en Internet, especialmente en las redes sociales) desde la perspectiva glotopolítica (ARNOUX, 2008, 2015, 2016 y 2018 y en prensa), este artículo se propone avanzar en el análisis de un programa oficial de uso del lenguaje claro y de la lectura fácil (entendidas como "prácticas de higiene verbal" según Cameron, 1995) a través del cual el Estado ${ }^{2}$ argentino entabla comunicación con la ciudadanía. Esta campaña se despliega en el ámbito jurídico y en un contexto político que promueve la transparencia como eje central del gobierno del "cambio"3 que está en el poder desde diciembre de 2015.

\footnotetext{
2 Por "Estado" entendemos tanto el país dentro de sus fronteras como la institución administrativa gubernamental de ese país. En este caso, aludimos al segundo caso.

${ }^{3}$ La alianza que está a cargo del Poder Ejecutivo (2015-2019) se denomina justamente "Cambiemos" y une fuerzas de un partido político histórico como es la Unión Cívica Radical (UCR) y uno más nuevo como es el PRO.
} 
El trabajo se interroga acerca de si estos modos de leer y de escribir adoptados desde el Estado para arbitrar el orden lingüístico y discursivo con la (supuesta) voluntad de "empoderar a los ciudadanos" inciden (o no) en la transformación de la distribución social del capital simbólico en el plano del lenguaje en lo que atañe a la comunicación experta, en este caso jurídica, oficial.

La iniciativa estatal se presenta como una respuesta "natural" a las dificultades que tienen los ciudadanos para comprender leyes, reglamentos, sentencias, contratos y otros documentos jurídicos. Como ya se señaló, esta intervención en las prácticas lingüísticas y discursivas se inscribe en políticas más amplias llevadas adelante por el aparato estatal que declara impulsar medidas públicas democráticas, transparentes, justas, equitativas e inclusivas en cuanto a los derechos civiles. Con este gesto, se desea proyectar una imagen de un Estado abierto, cercano, (pos)moderno, despolitizado, pragmático, técnico y flexible a las demandas de equidad e inclusión social.

En el caso del lenguaje claro caracterizado por su tendencia justamente a la claridad, precisión y concisión, Lara (2006) señala que es un tópico del Renacimiento con antecedentes en la Edad Media, en la plana locutio, que se opone al considerado lenguaje barroco y sobrecargado. Cada vez que se produce un cambio en la tecnología de la escritura, es decir, que mutan las condiciones materiales, resurge el tema de la claridad, la sencillez y la brevedad a la hora de comunicar. Su reaparición en el presente adquiere, claro está, un sentido histórico y una función social diferente. Más allá de los aspectos declarativos, se vislumbran motivaciones políticas y económicas que orientan esas medidas: responden, entendemos, a una funcionalización del lenguaje acorde con la racionalidad neoliberal tecnocrática hegemónica de la eficacia, la eficiencia, la rapidez y el lucro (reducción costo-incremento beneficio), semejante a la lógica empresarial en la que los destinatarios son construidos e interpelados como clientes y/o consumidores de los servicios públicos más que como ciudadanos.

Nuestra investigación se inscribe en el enfoque glotopolítico (ARNOUX, 2016 y LAURÍA, 2017) que estudia la dimensión política de los fenómenos lingüísticos y discursivos abordados y los examina como intervenciones, muchas veces en disputa, en el espacio público del lenguaje que tienden a reproducir o transformar una estructura de clases sociales dominante, construyendo las subjetividades necesarias en cada instancia histórica Con especial énfasis, se identifican y relevan las representaciones e ideologías del lenguaje que sostienen dichas acciones (ARNOUX; DEL VALLE, 2010). Desde el punto de vista metodológico, el trabajo adopta una metodología de tipo cualitativa, cuyo fin no es verificar hipótesis o realizar predicciones sino, más bien, acceder a la construcción de los sentidos asociados al tema abordado a través de las herramientas del análisis del discurso en tanto práctica eminentemente interpretativa (ARNOUX, 2006).

Por otra parte, nos nutrimos igualmente de otros planteos tales como los que provienen de la sociolingüística crítica como son los estudios de Duchêne y Heller (2012), Lara (2015) y Heller y McElhinny (2017) que también exploran el lenguaje como un recurso que produce, reproduce o disputa la distribución desigual en el acceso a otras clases de recursos tanto simbólicos como materiales. En definitiva, ponen en juego la relación entre lenguaje, política y cambio social. 
Inicialmente, se hará un repaso general de los modos de escribir y leer en el ámbito de la justicia. Posteriormente, el trabajo se focalizará en la descripción y análisis del programa global "Justo vos" en lo que atañe a la cuestión del lenguaje claro en particular. Y, finalmente, se discutirán las implicancias glotopolíticas que entraña dicho proyecto proveniente de la esfera estatal.

\section{EN TORNO A LOS MODOS DE ESCRIBIR Y DE LEER EN EL ÁMBITO DE LA JUSTICIA}

Las representaciones que circulan en torno al lenguaje administrativo en general y al jurídico en particular lo evalúan como críptico, oscuro, hermético, ambiguo debido a, entre otros aspectos, la presencia de oraciones y párrafos extensos; el uso de la voz pasiva; el abundante empleo de verbos débiles y de elementos de negación; la recurrencia de términos jergales, expresiones latinas, y de los llamados neologismos y arcaísmos así como también por la falta de un diseño y una disposición u organización textual adecuados.

El lenguaje claro, también denominado, en algunos casos con el mismo significado y en otros con sutiles diferencias de alcance, lenguaje llano o lenguaje ciudadano (plain language en inglés) nació en el mundo anglosajón entre las décadas del sesenta y setenta con el objetivo de revertir esas representaciones y modificar las prácticas ${ }^{4}$. Para ello, se buscó reemplazar los modos de escribir dominantes por otros que privilegiaran la claridad, la concisión, la brevedad, la comprensibilidad, la facilidad y la accesibilidad a partir no solo de ciertos esquemas textuales sino también de la combinación de elementos verbales con otros visuales y multimodales. Los principales destinatarios son los ciudadanos en general y, en mayor medida, personas con distintas clases de discapacidad intelectual o migrantes que no manejan la lengua oficial del país.

En el presente, el uso del lenguaje claro en la administración pública es tan común a nivel global que hasta se conmemora el 13 de octubre como el día internacional del lenguaje claro debido a la sanción de una ley federal que firmó el expresidente de los Estados Unidos Barack Obama en 2010 que fomenta el uso de dicha modalidad. Asimismo, existe una Academia del Plain Language, para el inglés: http://www.plainlanguageacademy.com/, que es una fundación privada con base en los EEUU, Inglaterra y Canadá. La institución ofrece un curso de aprendizaje en línea diseñado para equipar y entrenar a quienes lo tomen con habilidades para mejorar la realización de escritos especializados. El curso tiene seis bloques secuenciales con nutrida información procedimental acerca de este saber técnico, que se pueden realizar de manera individual o en forma completa.

Por otro lado, hay dos asociaciones internacionales: una llamada Plain Language Association International http://plainlanguagenetwork.org/, un organismo sin fines de lucro conformado por activistas y practicantes de esta modalidad. La otra es una asociación internacional llamada Clarity http://www.clarity-international.net, que, según

\footnotetext{
${ }^{4}$ El llamado lenguaje fácil es, según sus ideólogos y militantes, un tipo de práctica e intervención discursiva distinta que el lenguaje claro, que se arroga otros postulados de base, realiza distintos tipos de materiales y se dirige a públicos diferentes. No obstante, en muchos documentos a veces estas dos modalidades se superponen y confunden.
} 
se indica en su página web, es una red mundial de profesionales fundada en el Reino Unido en 1983 que se compromete a propiciar el lenguaje legal claro en todas las lenguas históricas. Tiene más de 650 miembros en 50 países, por lo que la convierte en la organización más grande de este tipo. Entre sus integrantes, hay jueces, abogados, funcionarios de organizaciones gubernamentales y no gubernamentales, así como correctores, traductores y editores. La organización cuenta con representantes oficiales. La Argentina, a través de la misma persona, es socia de ambas entidades y, en el segundo caso, participa además como miembro del Consejo Directivo.

En cuanto a la lectura fácil, esta modalidad surgió en el mundo escandinavo, concretamente en Suecia en los años sesenta. No dispone de un estándar fijo, sino que propone varios niveles de adaptación de los textos puesto que se postula que es difícil redactar un contenido que se amolde a todos los grados y las capacidades de comprensión o a todas las personas que tengan problemas de lectura y escritura. El nivel 1 es el más sencillo, en él abundan las ilustraciones y el texto es de menor extensión además de carecer de complejidades sintácticas. El nivel 2 incluye vocabulario y expresiones de la vida cotidiana, verbos fáciles e ilustraciones. El nivel 3 es el más complejo porque el texto es más extenso e incluye algunas palabras poco usuales y, a veces, con sentido figurado. La presencia de ilustraciones es, en este último caso, escasa._Se asevera que, si bien las medidas de accesibilidad benefician a la población en general, son más provechosas para colectivos específicos vulnerables y/o marginalizados como, por ejemplo, las personas con discapacidad intelectual, dificultades cognitivas o educación limitada; los hablantes no nativos de una lengua; los niños nativos con baja alfabetización y los migrantes recientes 5 .

En la Argentina, en octubre de 2017, se realizó en el Honorable Senado de la Nación, la Primera Jornada Internacional de Lenguaje Claro. Como resultado de ese evento y siguiendo algunas iniciativas que se habían implementado con anterioridad en Latinoamérica (Becker, en prensa), se acordó conformar una Red Nacional de Lenguaje Claro en la que participaran representantes de los tres poderes del Estado (Ejecutivo, Legislativo y Judicial). El acuerdo tiene como principal objetivo transmitir de manera clara y sencilla el contenido de los documentos que generan las instituciones públicas, en especial leyes, decretos y resoluciones con el fin de allanar su comprensión y acceso universal para todos los ciudadanos.

En síntesis, si bien las modalidades de lenguaje claro y de lectura fácil tienen cada una sus propias características, comparten el propósito de que los ciudadanos capten la información que necesitan para su vida cívica y social sin problemas. Las líneas directrices de ambos proyectos señalan que la claridad en el lenguaje de todos los actos comunicativos emitidos por parte de los organismos del Estado desburocratiza las prácticas y, por ende, colabora en el adecuado ejercicio de las responsabilidades, los derechos y los deberes a la vez que fortalece la democracia, la transparencia, la confianza $\mathrm{y}$, sobre todo, la justicia y la inclusión social.

\footnotetext{
5 La lectura fácil tiene sus fundamentos en las normas de las Naciones Unidas sobre igualdad de oportunidades para las personas con discapacidad.
} 


\section{EL PROGRAMA “JUSTO VOS”: DESCRIPCIÓN Y ANÁLISIS}

“Justo vos" https://www.argentina.gob.ar/justovos 6 es un programa de alcance nacional, creado por la resolución ministerial $\mathrm{N}^{\mathrm{o}} 431 / 16$, cuya finalidad es la promoción de acciones de justicia cotidiana preventiva del Ministerio de Justicia y Derechos Humanos de la Nación para impulsar, en definitiva, un proceso de cambio cultural y de formación en valores. Su punto de partida es que todos los habitantes del país son actores en los ámbitos en que cada uno se desenvuelve y que por medio del ejercicio constante y permanente de actos justos participan en la construcción de la sociedad, valga la redundancia, justa y pacífica que se pretende instaurar. Se manifiesta que un cambio en materia de justicia requiere adquirir ante todo predisposición al diálogo y al consenso, dejando de lado una dinámica de confrontación permanente; el Estado debe dar el ejemplo y trabajar en las dimensiones no judiciales de la justicia proporcionando servicios que fomenten valores democráticos que unan a los argentinos; y haciendo conocer y entender las leyes, los derechos y las obligaciones para lo que resulta indispensable expresarlos en lenguaje claro. La búsqueda de la accesibilidad a la información es, así, el propósito primordial que orienta la iniciativa estatal.

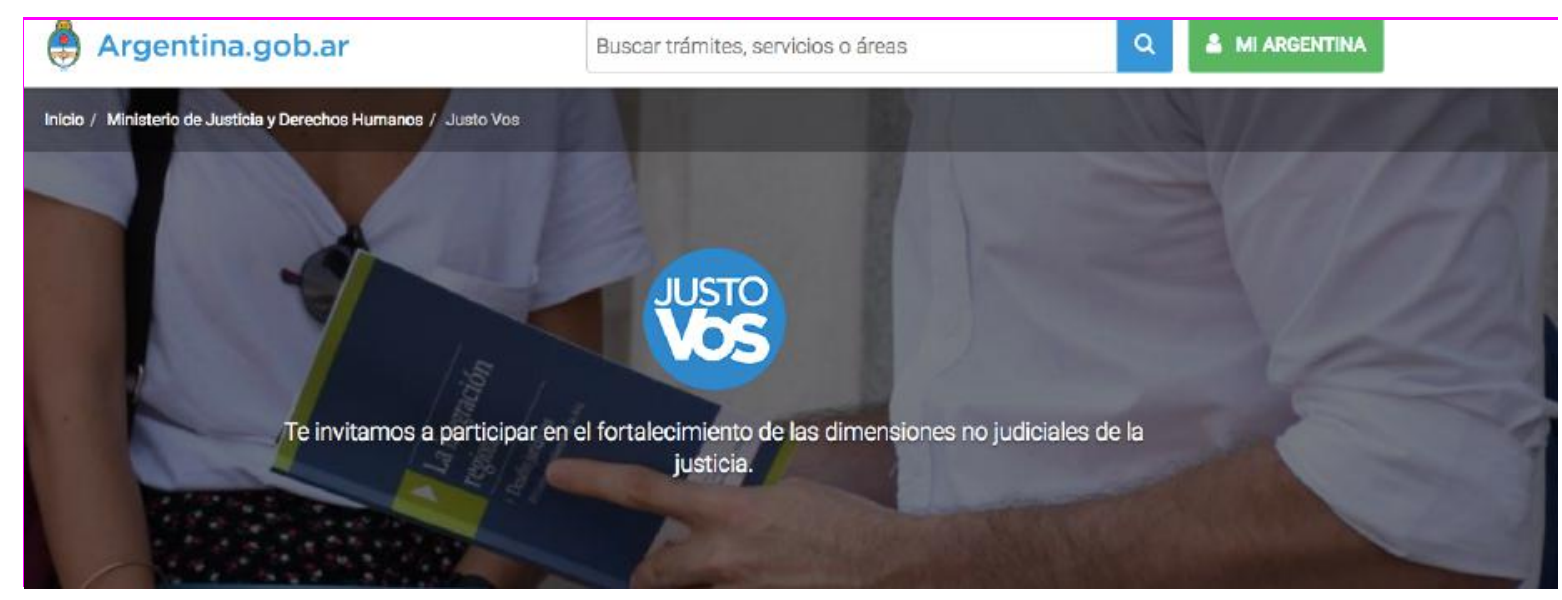

El programa "Justo vos" consta de los siguientes ejes:

\footnotetext{
${ }^{6}$ Es interesante analizar dos aspectos de la denominación del programa "Justo vos". En primer lugar, la estrategia de recurrir a la segunda persona singular "vos" que se emplea en el español de la Argentina en lugar del más generalizado "tú" en el mundo hispánico y en contraste con el pronombre de mayor distancia "usted". De esta manera, se interpela directamente al ciudadano desde una relación de mucha cercanía y confianza. Este recurso es bastante utilizado en la actualidad en las propagandas del partido gobernante para establecer la comunicación con las personas de manera individualizada con cordialidad pero a la vez también con familiaridad y espíritu amistoso. En segundo lugar, la palabra "justo" abre un doble juego de sentido: algo es justo cuando la justicia así lo decide, es decir, cuando se obra conforme a la justicia y a la razón. Pero, además, "justo" se usa en el español de la Argentina para referirse a que alguien o algo es el o lo adecuado, el o lo correcto para una determinada situación. De ese modo, el programa, según la segunda acepción de "justo", se dirige a quien es el destinatario preciso.
} 


\section{Ejes del programa}

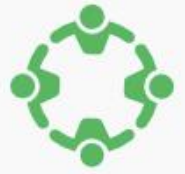

\section{Educación en valores}

Ofrecemos espacios de reflexión en torno a la justicia como valor.<smiles>c1ccccc1</smiles>

\section{Protección de} datos personales

Agrupamos herramientas para proteger la información y los datos personales.

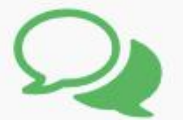

\section{Derechos Humanos}

Concientizamos y acercamos herramientas para su correcto ejercicio.

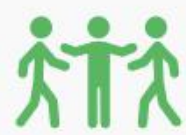

\section{Mediación comunitaria}

Promovemos la resolución de conflictos a través del diálogo.

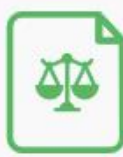

\section{Justicia en lenguaje claro}

Hacemos más accesibles

las leyes, sentencias,

resoluciones y decretos.

Nos focalizamos en particular en la sección "Justicia en lenguaje claro", cuyo apartado "Derecho fácil" se propone ayudar a comprender la información jurídica a través del desarrollo y la difusión de servicios lingüísticos y discursivos generados ad hoc que reformulan y explican textos reglamentarios.

La plataforma ofrece seis recursos:

\section{Derecho Fä́rll}

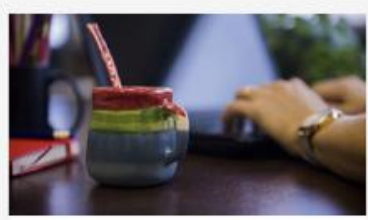

Ley Simple

Explicamos las principales leyes, decretos y resoluciones de manera sencilla para que conozcas tus derechos y obligaciones.

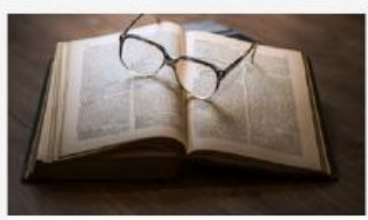

Wiki lus

Construimos con la comunidad un glosario de términos jurídicos con explicaciones que todos podamos entender.

$\rightarrow$ Vermas

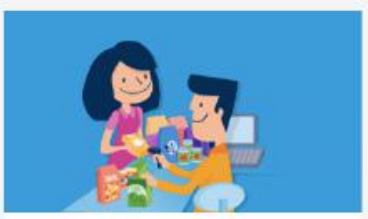

Justicia Cerca

Acercamos la justicia a la gente orientándola en situaciones cotidianas vinculadas con la ley. 


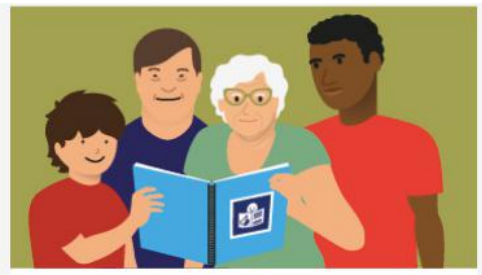

\section{Lectura Fácil}

Adaptamos y redactamos textos en lectura fácil para que conozcas y comprendas tus derechos.

\section{$\rightarrow$ Ver más}

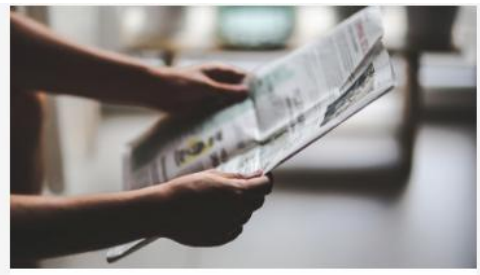

\section{Boletín Oficial Fácil}

Seleccionamos normas del Boletín Oficial y las redactamos en lenguaje claro para mantenerte actualizado.

\section{$\rightarrow$ Ver más}

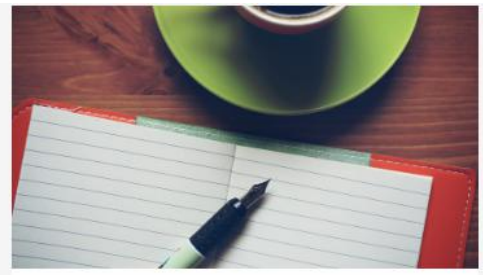

\section{Capacitación}

Damos capacitaciones sobre lenguaje claro para que puedas aplicarlo en los textos de todos los días.

$\rightarrow$ Ver más

Ley Simplo > Trabajo > cuenta sueldo
Cuenta SUeldo
Ley 26.704
La cuenta sueldo está regulada para que cobres tu salario de una
manera segura, registrada y tengas todos los beneficios de una
cuenta bancaria.

1) Ley simple: se explican, a partir de la adopción de un formato textual de preguntas y respuestas breves, así como del empleo de un léxico simple y cotidiano, los principales documentos legales. Se muestra como ejemplo de la ley $\mathrm{N}^{0} 26704$, el ítem "cuenta sueldo" de la categoría "trabajo": 
2) Wiki Ius ${ }^{7}$ : se trata de un glosario de términos jurídicos que se construye en línea de modo colaborativo, participativo por la comunidad en su conjunto. Las voces consignadas exhiben explicaciones y definiciones concisas. El recurso opera como una suerte de "traductor", en términos intralingüísticos, de tecnicismos:

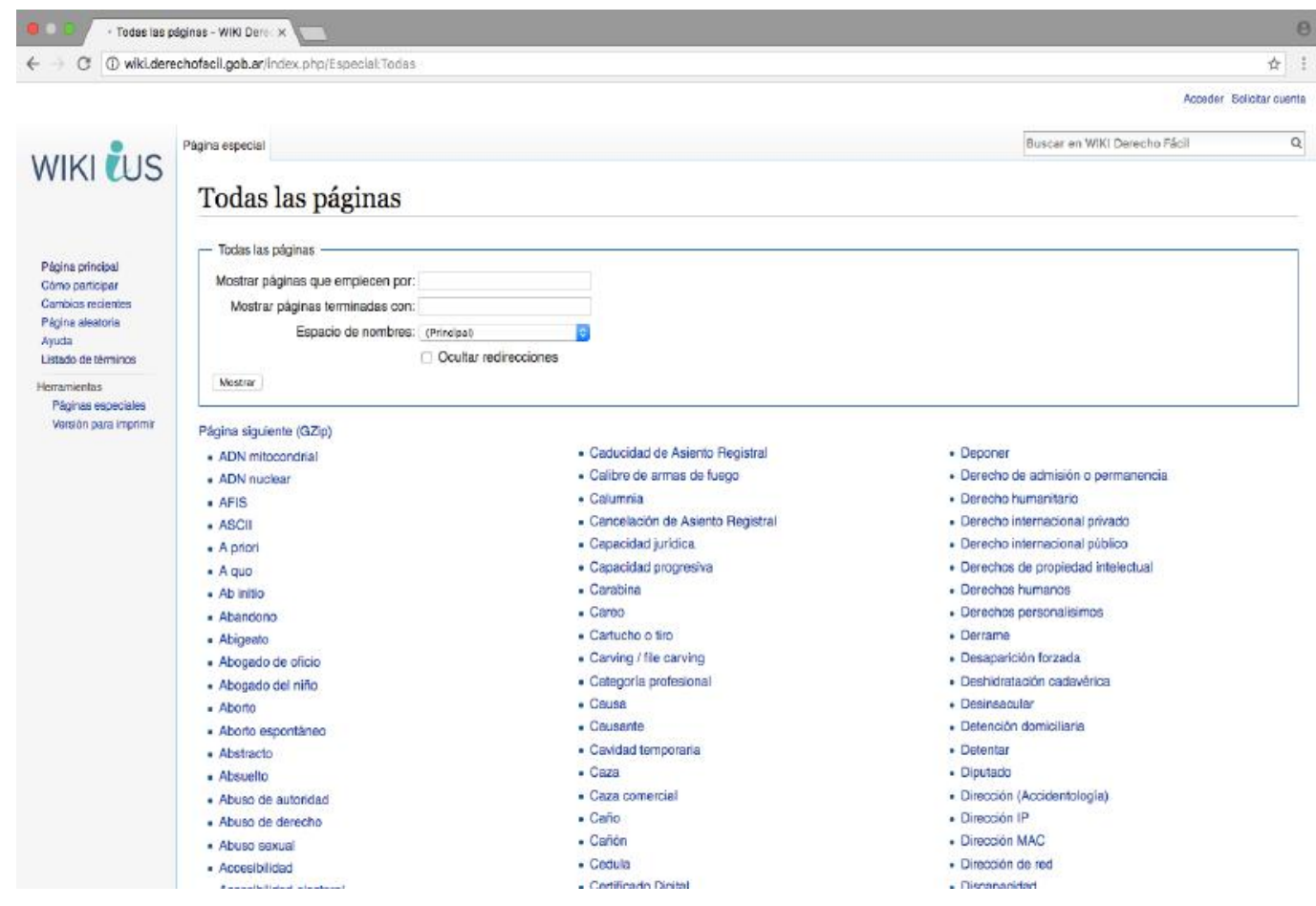

El listado de voces, sintagmas y expresiones técnicas ordenadas de forma alfabética es extenso e incluye también nombres propios del ámbito de la justicia. A continuación, ilustramos cómo funciona el procedimiento con el caso de la palabra "dolo". La secuencia explicativa comienza con la definición según lo que se entiende por ella en el derecho civil, primero; y en el derecho penal, después. Luego, se ofrecen algunos sinónimos para terminar con la mención de las fuentes y las referencias donde se puede consultar más información acerca de su uso.

\footnotetext{
${ }^{7}$ Resulta sumamente significativo, desde el punto de vista discursivo, que en el marco de un programa de lenguaje claro y accesible para toda la ciudadanía que tiene como eje vertebrador el uso de palabras y expresiones sencillas y conocidas para todos, se decida titular uno de los recursos del programa estatal con una palabra latina como es "Ius", que supone claramente cierto conocimiento lingüístico y de mundo. Este gesto se puede interpretar, así, como un equívoco, un acto fallido, un lapsus del orden de lo inconsciente que aflora en el discurso y que permite revelar la condición ideológica del programa, esto es, perpetuar la desigualdad lingüística pese a la manifiesta declaración de democratización de la palabra y de su acceso.
} 


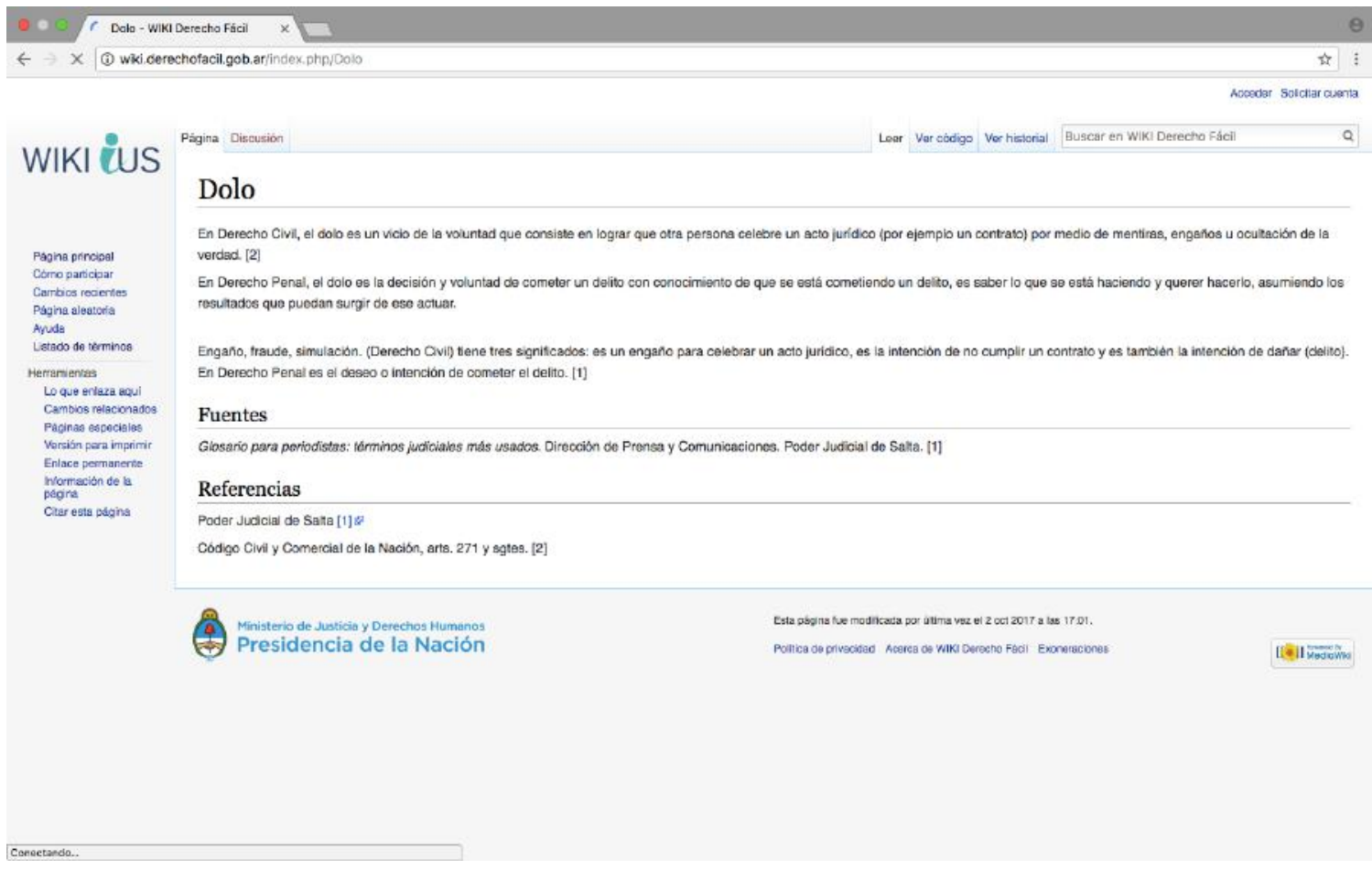

3) Justicia cerca: semejante al recurso de la ley simple, expone y orienta, con un formato textual de preguntas y respuestas breves, lo que se debe hacer en situaciones cotidianas vinculadas con la ley. En el ejemplo expuesto abajo, se indican cuáles son los pasos a seguir en el caso de sufrir un acoso callejero en la ciudad de Buenos Aires:

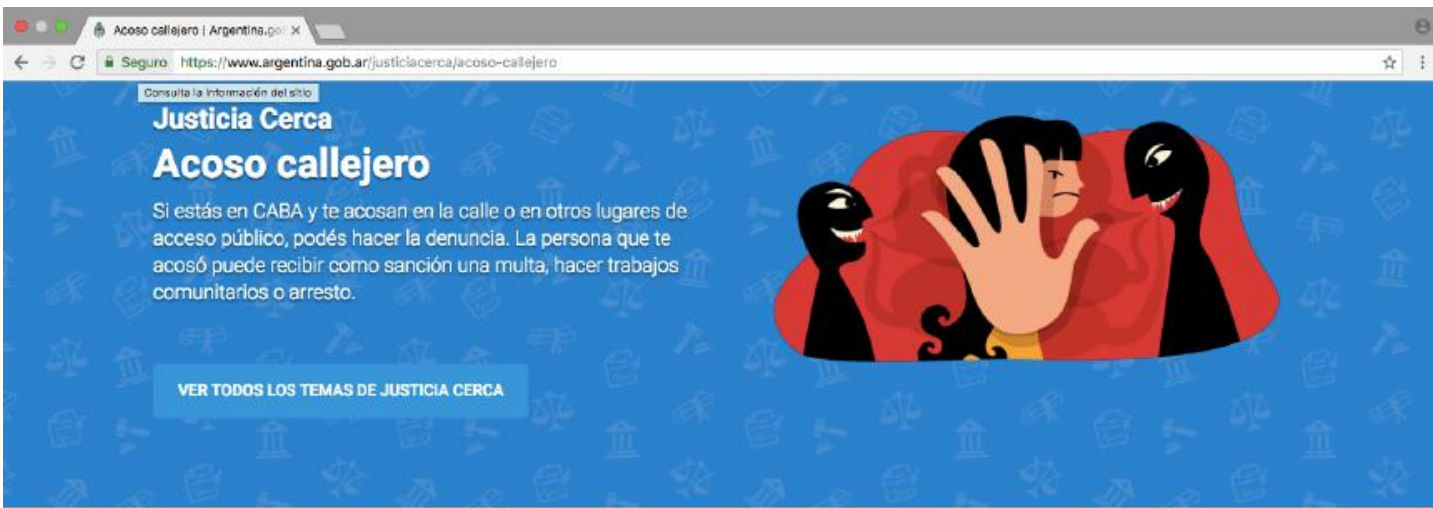

LO QUE TENÉS QUE SABER

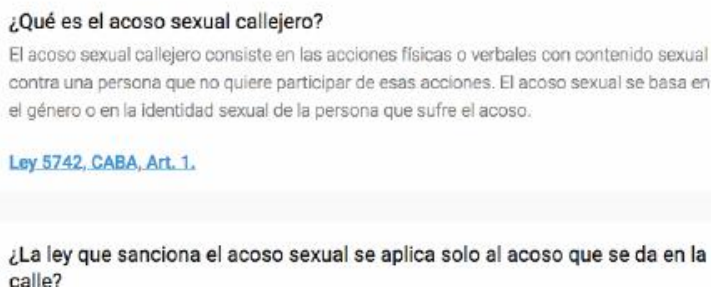

DATOS DE CONTACTO

Atención a Mujeres Victimas de Delitos contra la Integridad Sexual

Piedras $1281,1^{\circ}$, CABA

Teléfono $4300-8615$.

Atención: lunes a viernes de $B$ a 15 hs. Hacé la denuncia:

http://www.buenosaires, gob.ar/desarrollohu

manoyhabitat/mujer/acoso-

callejero/denuncia-el-acoso-callejero es

Brinda asistencia, orientación y 
4) Lectura fácil: se adaptan textos legales cruciales para la ciudadanía. Por ejemplo, la Constitución Nacional se reformula hasta el artículo 43, es decir, se atiende solamente la primera parte que incluye el primer capítulo "Declaraciones, Derechos y Garantías" (artículos 1 al 35) y el segundo capítulo "Nuevos Derechos y Garantías" (artículos 36 al 43). Como se sabe, la Carta Magna, luego de la reforma del año 1994, tiene en total 129 artículos por lo que queda afuera la segunda parte completa que se refiere al tema de las "Autoridades de la Nación":

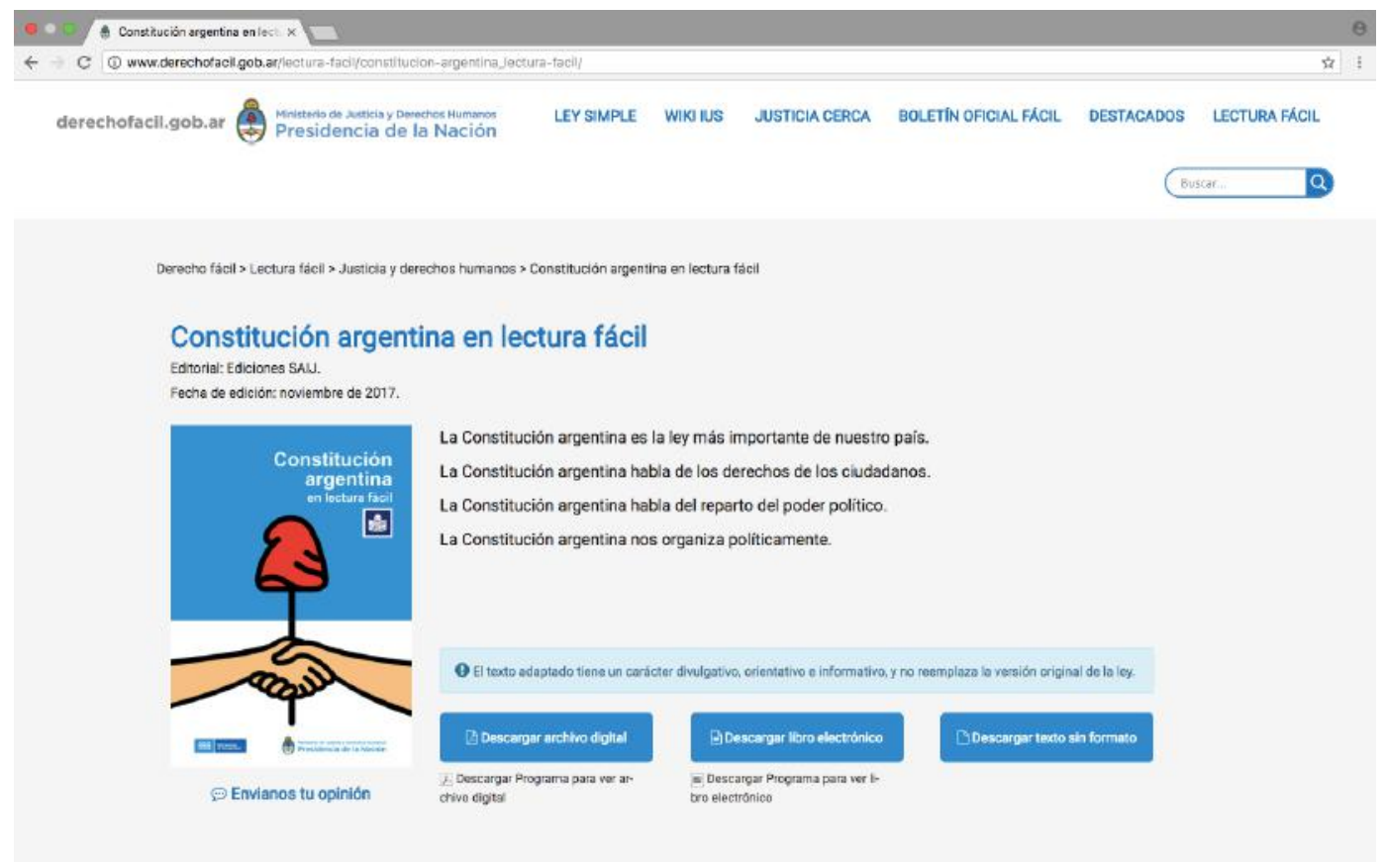

Se muestra también la página dedicada al "Preámbulo", que se analizará con detalles en la próxima sección:

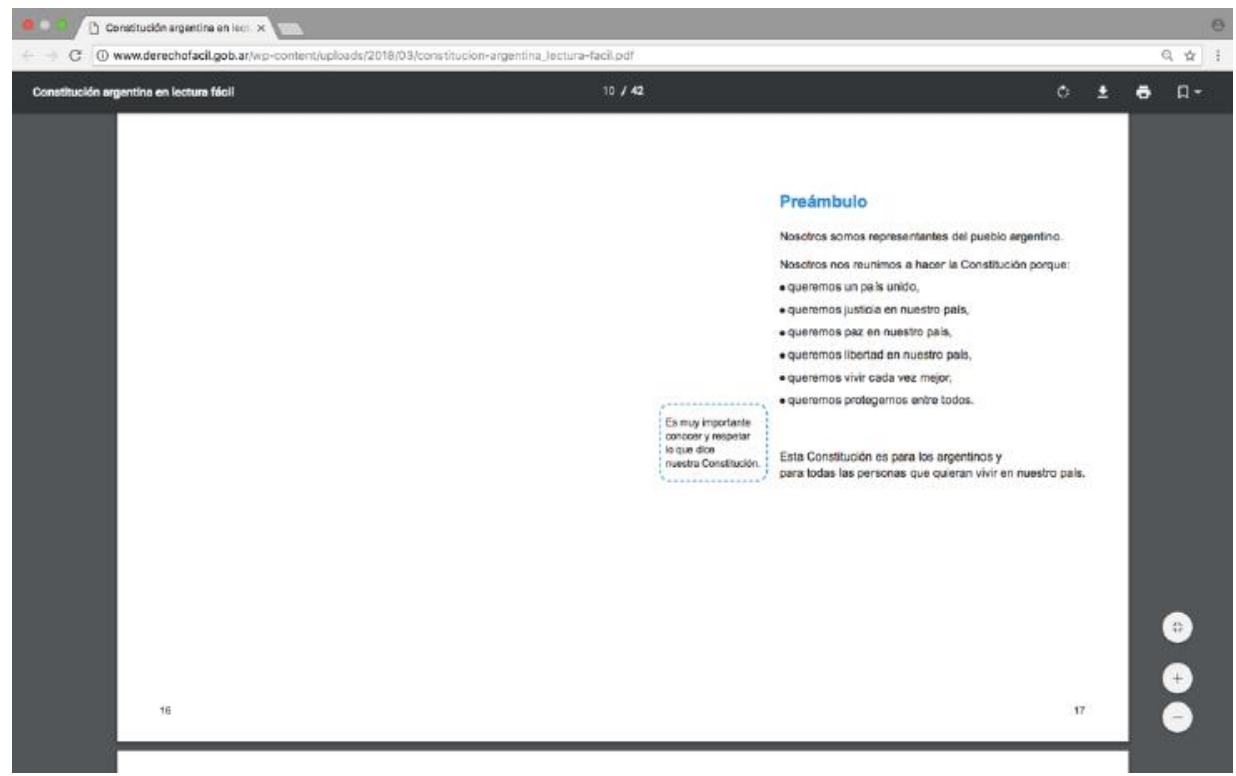


5) Boletín oficial fácil: se seleccionan resúmenes de las normas más importantes que se publican diariamente en la primera sección "Legislación y avisos oficiales" del Boletín Oficial y se redactan en lenguaje claro. Esta página se actualiza todos los meses:

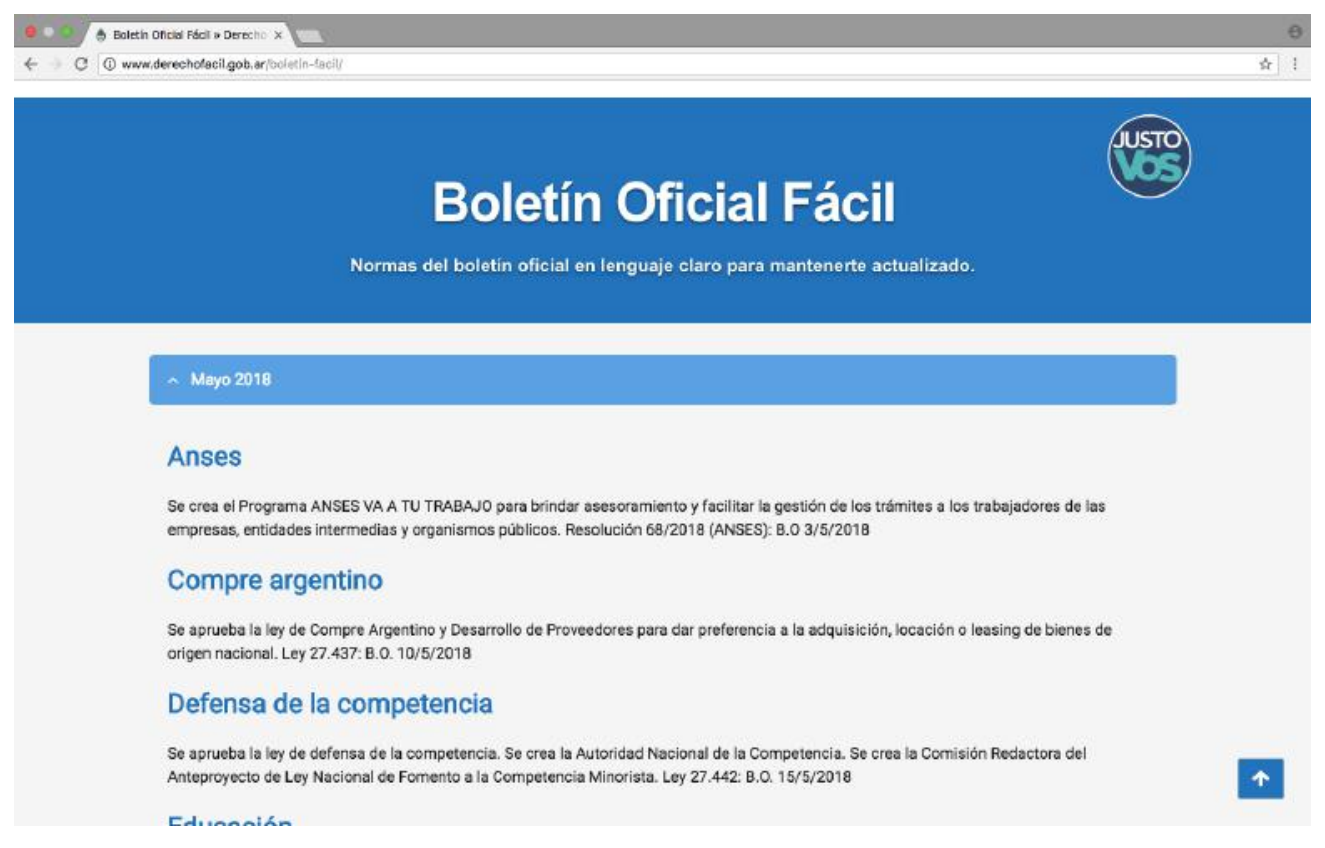

6) Capacitaciones: este último apartado brinda información sobre los cursos que se ofrecen a funcionarios de organismos oficiales. Los seminarios de perfeccionamiento y actualización están a cargo de la Dirección Nacional del Sistema Argentino de Información Jurídica (SAIJ) para potenciar el uso del lenguaje claro. Toman como base los lineamientos y pautas presentes en el Manual SAIJ:

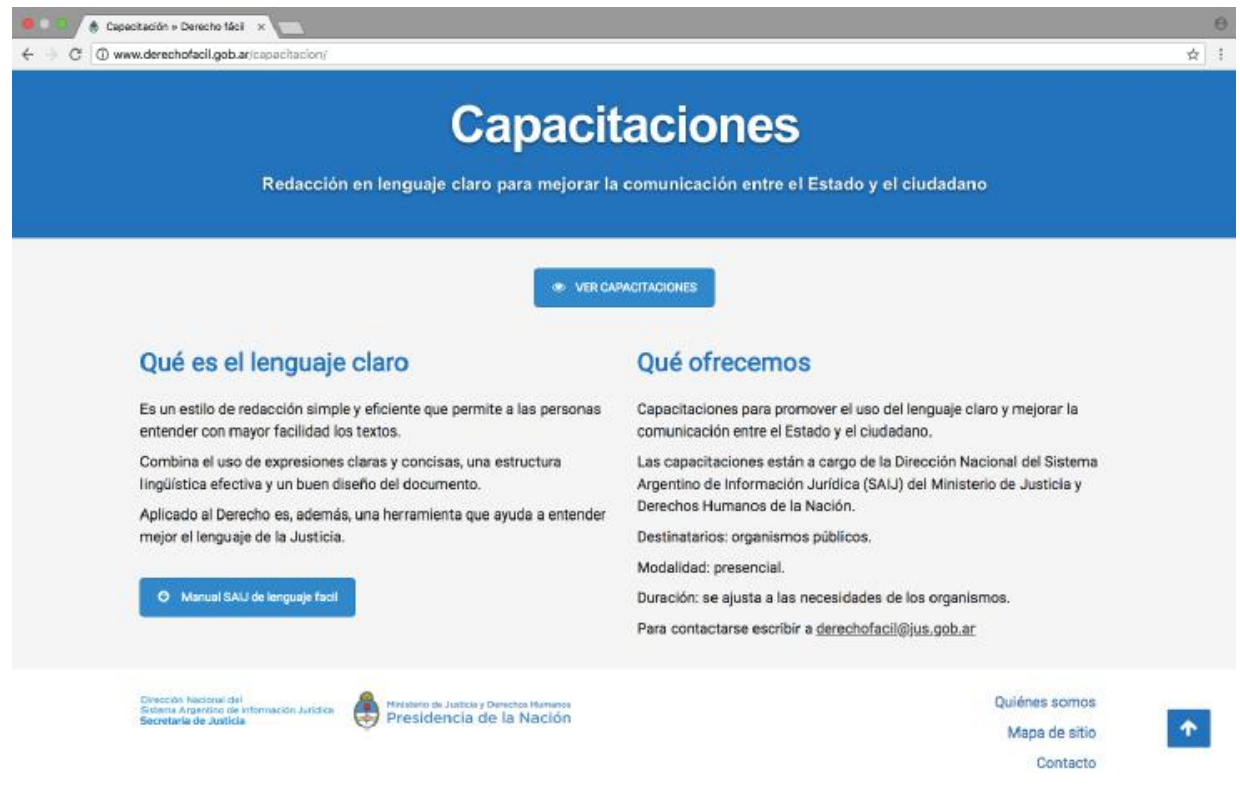


Luego de una primera aproximación, se advierte que la principal fuente bibliográfica (no mencionada) de referencia del Manual es la Federal Plain Language Guidelines de los Estados Unidos editada en 2010 https://www.plainlanguage.gov/guidelines/. Sí, en cambio, se cita una serie de guías oficiales de países hispanohablantes como las de España, Perú y México. El Manual, que actúa como parámetro de referencia del programa "Justo vos", constituye un catálogo de indicaciones para redactar contenidos oficiales en el nivel de adaptación del lenguaje ciudadano. En el mismo instrumento lingüístico, se define el alcance de la expresión "lenguaje ciudadano": "[...] los contenidos están destinados a personas con educación básica, sin discapacidad intelectual y sin conocimientos técnicos sobre la materia que queremos comunicar" (p. 4).

Dos son las premisas que lo guían: la primera apunta a que la información compleja no debe ser suprimida, sino, por el contrario, expresada de modo sencillo. La segunda asevera que los términos técnicos también deben ser explicados. Para ello, se presenta un conjunto de pautas lingüísticas y discursivas para tener en cuenta a la hora de la redacción de textos adaptados a la modalidad de lectura fácil. Subyace a dichas indicaciones la idea de que las estructuras o elementos breves, comunes y directos son más fáciles de comprender que los extensos, inusuales e indirectos. De ahí que se recomiende emplear patrones léxicos, oracionales, discursivos, estilísticos y retóricos estandarizados:

- Estructura del texto: una sola idea por oración. Para ello se deben eliminar frases compuestas o se deben hacer enumeraciones y listas; oraciones cortas de no más de 120 caracteres; estructura básica (sujeto + verbo + complementos (OD, OI, circunstanciales); sujeto expreso; voz activa; párrafos cortos que no superen las seis líneas; un tema por párrafo; signos de puntación (se aconseja utilizar punto y paréntesis; y se desaconseja el empleo de coma, dos puntos, corchetes y barra para evitar digresiones); para las mayúsculas se sugiere seguir la norma general; en el caso de siglas, si su uso es muy corriente, se opta por usarlas con preferencia a la forma extendida; los números arábigos se deben escribir en cifras y no en letras, y se deben evitar los números romanos. Se propone no utilizar porcentajes ni fracciones, y escribir las fechas en forma completa.

- Estilo del texto: redacción directa (llegar rápidamente a la información que se considere central; eliminar las palabras innecesarias para ganar brevedad y sencillez); trato personal (para generar cercanía con el lector se deben utilizar pronombres personales para interpelarlo e involucrarlo, eliminar cuestiones abstractas y redactar oraciones cortas); redacción en positivo (evitar las formas negativas y las dobles negaciones).

- Vocabulario: términos corrientes en lugar de tecnicismos, inclusivos y no discriminatorios.

- Pautas de diseño: alineación del texto a la izquierda; colocación del número de página en la parte inferior, a la derecha en página impar y a la izquierda en impar; empleo de letras en tamaño 14 y no usar efectos tipográficos como sombras, subrayados o cursivas; utilización de viñetas para enumerar. En este bloque se indican, además, algunos lineamientos para escribir en páginas web, blogs y otros recursos multimodales. 
Con el cometido de ilustrar los preceptos consignados, el Manual adopta un determinado dispositivo textual normativo: un cuadro de doble entrada (al estilo de un appendix probi) bajo los títulos "Evitamos" (con un dedo pulgar para abajo en rojo) / "Preferimos" (con un dedo pulgar para arriba en verde). Estos rótulos de las columnas constituyen formas más mitigadas o atenuadas (NOGUEIRA, 2016) de las expresiones "Don't say" / "Say" que encabezan el mismo formato en la guía de los Estados Unidos. A modo de ejemplo, se citan algunos recortes en las versiones en español y en inglés para observar la influencia del formato discursivo del segundo sobre el primero:

\section{- Una idea por oración}

\begin{tabular}{|l|l|}
\hline \multicolumn{1}{|c|}{ EVITAMOS } & \multicolumn{1}{c|}{ PREFERIMOS } \\
\hline Las expensas por el mantenimiento del & $\begin{array}{c}\text { Sobre los gastos de expensas del complejo } \\
\text { complejo vacacional deben abonarse según la } \\
\text { vacacional tenés que saber que: } \\
\text { proporción que figure en el contrato de }\end{array}$ \\
$\begin{array}{l}\text { compra y deben estar al día para que puedas } \\
\text { usar tu semana. }\end{array}$ & $\begin{array}{l}\text { El contrato debe indicar la } \\
\text { proporción que te corresponde pagar. }\end{array}$ \\
& $\begin{array}{l}\text { Debés tener las expensas al día para } \\
\text { poder usar tu semana. }\end{array}$ \\
\hline
\end{tabular}

\begin{tabular}{|c|c|}
\hline DON'T SAY & SAY \\
\hline $\begin{array}{l}\text { Each completed well drilling application } \\
\text { must contain a detailed statement including } \\
\text { the following information: the depth of the } \\
\text { well, the casing and cementing program, the } \\
\text { circulation media (mud, air, foam, etc.), the } \\
\text { expected depth and thickness of fresh water } \\
\text { zones, and well site layout and design. }\end{array}$ & $\begin{array}{l}\text { With your application for a drilling permit, } \\
\text { provide the following information: } \\
\text { - Depth of the well; } \\
\text { - Casing and cementing program; } \\
\text { - Circulation media (mud, air, form, } \\
\text { etc); } \\
\text { - Expected depth and thickness of } \\
\text { fresh water zones; and } \\
\text { - Well site layout and design. }\end{array}$ \\
\hline
\end{tabular}

\section{- Trato personal}

\begin{tabular}{|l|l|}
\hline \multicolumn{1}{|c|}{ EVITAMOS } & \multicolumn{1}{c|}{ PREFERIMOS } \\
\hline En caso de pérdida o robo de un cheque, & Si perdiste o te robaron un cheque, informalo \\
debe dirigirse a la entidad financiera. & al banco. \\
Con el certificado es posible viajar gratis. & Con el certificado podés viajar gratis. \\
\hline
\end{tabular}

\begin{tabular}{|c|c|}
\hline DON'T SAY & SAY \\
\hline Copies of tax returns must be provided. & You must provide copies of your tax returns. \\
\hline
\end{tabular}

Lo expuesto hasta ahora hace que surja un interrogante: ¿estos modos de leer y escribir impactan positivamente e, incluso, revierten la desigualdad de acceso al discurso jurídico $y$, por extensión, la desigualdad social o, por el contrario, son una suerte de "trampa", que perpetúa, aunque en términos diferentes, la distribución social inequitativa en el plano del lenguaje? Entendemos que la afirmación de que tanto el lenguaje claro como la lectura fácil aumentan la accesibilidad y la comprensión es si no difícil de demostrar (no es nuestro interés calificar la propuesta como verdadera o falsa o como buena o mala), es 
por lo menos relativa a determinados intereses que exceden el campo de lo meramente lingüístico y discursivo. La presunta claridad se logra, en varios aspectos, a costa o directamente sacrificando la precisión garantizada por el léxico técnico como, por ejemplo, en el caso de "dolo" mostrado más arriba donde se simplifica tanto la definición que se pierde su precisión conceptual. La información explicada de manera sencilla o el reemplazo de términos específicos por otros más usuales y conocidos ("percibir los haberes" por "cobrar el salario"; "dolo" por "fraude"; "entidad financiera" por "banco") puede, en algunas ocasiones, plantear dudas sobre el alcance semántico -y mucho más serio las derivaciones jurídicas- de las expresiones en juego. Dicho en otras palabras, pese a la promesa de claridad, lo que sucede es que se regula y restringe lo que se puede decir y, sobre todo, cómo decirlo. La búsqueda de ese ideal estilístico compromete de modo grave el contenido puesto que necesariamente implica una reducción de la información al aplicar una serie de operaciones de reformulación intralingüística que producen, como corolario, una simplificación, una esquematización y, a veces, generan también un efecto de infantilización del discurso jurídico, máxime si se tienen en cuenta algunas imágenes (dibujos y gráficos) que acompañan el discurso verbal.

El propósito de un texto legal está orientado fundamentalmente a constituir la ley, no a explicarla. El hecho de que, a primera vista, el lenguaje claro y la lectura fácil parezcan "útiles" es un tema controversial en la medida en que su puesta en práctica despoja al lenguaje de la variedad de opciones disponibles, por un lado, y de cierta y necesaria complejidad sintáctica y textual propia de los géneros discursivos del terreno jurídico, por otro. Y esto, podemos pensar, redunda en un ocultamiento de información y/o en la no transmisión del significado pleno y cabal del mensaje, como en ciertos pasajes de la versión adaptada del "Preámbulo" de la Constitución Nacional. La Constitución de la Nación Argentina está encabezada por un pasaje conocido como "el Preámbulo", que expone los fundamentos y los objetivos de la ley suprema que rige en todo el territorio nacional. El cuerpo principal del texto introductorio se dedica a enumerar una serie de fines que conforman, en su totalidad, un programa de acción legislativo y político, cuyos agentes son "Nos (nosotros), los representantes del pueblo de la Nación Argentina", es decir, los diputados y los senadores que se reúnen elaboran y votan la Carta Magna. Dichos fines son los siguientes:

1) constituir la unidad nacional;

2) afianzar la justicia;

3) consolidar la paz interior;

4) proveer a la defensa común;

5) promover el bienestar general $y$

6) asegurar los beneficios de la libertad.

En la versión adaptada de este fragmento al lenguaje claro y a la lectura fácil sobresale una lista de estructuras formulaicas sintácticas breves, simples y directas que se repiten del tipo "queremos + objeto directo + en nuestro país", tal como es recomendado en las pautas de estilo del Manual SAIJ. Así pues, los fines constitucionales se reformulan del siguiente modo:

- queremos un país unido;

- queremos justicia;

- queremos paz; 
- queremos libertad;

- queremos vivir cada día mejor y

- queremos protegernos entre nosotros.

Esta secuencia compendia de manera por demás elocuente que el texto meta (el adaptado en la dimensión de la forma, del estilo) modifica sustancialmente el contenido del texto fuente (la Constitución Nacional) no solo a nivel del agente que lleva a cabo las acciones que se enuncian (el alcance del pronombre de la primera personal del plural "nosotros") sino principalmente la repercusión semántica (y, por extensión, podemos pensar, política y jurídica) de determinadas frases como "unidad nacional", "paz interior", "bienestar general" y "beneficios de la libertad" que acarrean y entrañan determinadas memorias, luchas e historicidades (temporalidades) propias del tipo de texto del que se trata, o sea, una ley. Asimismo, la aparición igualmente reiterada de verbos "fáciles" como "hablar" en las frases: "La Constitución argentina habla de los derechos de los ciudadanos" y "La Constitución argentina habla del reparto del poder político" tiñen al texto con un efecto de esquematismo, que se halla muy próximo a la tergiversación y a la ambigüedad de sus proposiciones, amén de que subestima las capacidades de comprensión lectora de gran parte de los ciudadanos.

Una estrategia distinta es, por su parte, la incorporación de vocabulario inclusivo y no discriminatorio en términos sexistas, étnicos, religiosos. La sustitución del lexema "hombres" por "personas" y la supresión de la invocación de la protección de Dios "fuente de toda razón y justicia" presentes originalmente en el texto constitucional ${ }^{8}$ obedecen a las exigencias del movimiento denominado lenguaje políticamente correcto ${ }^{9}$, que incluye acciones como las de la defensa de sexismo en la lengua y, últimamente, la del lenguaje inclusivo (ZOPPI FONTANA, 2015).

\section{OBSERVACIONES FINALES}

Para concluir, en este trabajo hemos analizado un caso puntual de regulación del discurso desde una perspectiva de indagación con vocación crítica como es la glotopolítica. A propósito, el investigador alemán Klaus Bochmann (2017, p. 15) asevera:

Este monopolio (los dueños del lenguaje) vese con máis claridade na regulación do discurso, posiblemente o aspecto máis importante e efectivo da glotopolítica. [...] O "poder da palabra", a posibilidade de

\footnotetext{
${ }^{8}$ En el Preámbulo se consigna: "Nos, los representantes del pueblo de la Nación Argentina, reunidos en Congreso General Constituyente por voluntad y elección de las provincias que la componen, en cumplimiento de pactos preexistentes, con el objeto de constituir la unión nacional, afianzar la justicia, consolidar la paz interior, proveer a la defensa común, promover el bienestar general, y asegurar los beneficios de la libertad, para nosotros, para nuestra posteridad y para todos los hombres del mundo que quieran habitar en el suelo argentino: invocando la protección de Dios, fuente de toda razón y justicia: ordenamos, decretamos y establecemos esta Constitución, para la Nación Argentina".

${ }^{9}$ El lenguaje políticamente correcto, por su parte, tiene como objetivo la sustitución de palabras y expresiones marcadas por algún tipo de discriminación (sexista, racista, religioso, por defectos físicos o deficiencias cognitivas) por otras palabras y expresiones que, conforme las pautas que guían el movimiento de lo políticamente correcto, no connotan tal efecto de segregación. En este sentido, el lenguaje políticamente correcto es un instrumento político potente de concientización y sensibilización cuya última meta es combatir la discriminación.
} 
influenciar e de manipular as persoas mediante a regulación da acción discursiva "desde arriba", é dicir, en consonancia cos intereses da clase dominante, non é só unha metáfora, senón que se trata dunha auténtica posición de poder, un posesionarse do idioma, e un posuír o idioma que fundamenta a hexemonía ${ }^{10}$.

Nos detuvimos brevemente en una campaña oficial actual de y para la Argentina, pero inscripta en una corriente mundial que persigue la homogeneización discursiva en el terreno de la justicia, reglamentando universalmente los modos de leer y de escribir con el inglés como punto de referencia, y sin considerar los contextos y las condiciones de producción, circulación y recepción específicos. Las implicancias de esta propuesta no son solo retóricas, sino que son esencialmente de carácter político y socioeconómico. En efecto, las prácticas lingüísticas y discursivas estandarizadas que se impulsan sustentadas en determinadas representaciones ideológicas del lenguaje- responden a las fuerzas económicas imperantes en la medida en que, como dijimos en la introducción, favorecen el rendimiento de herramientas informáticas y de dispositivos digitales ya que al traducirlas reducen costos y tiempos a la vez que captan mercados unificados más amplios.

Además, si bien el orden democrático legitimado a escala global manifiesta adoptar una política que se inclina justamente a la democratización de la práctica del lenguaje, ciertos modelos de regulación discursiva, como el visto en el ámbito de la justicia que buscan clausurar la interpretación de la ley y, con ello, que los destinatarios no problematicen sus alcances, tienden al control social y al mantenimiento del status quo reforzando o profundizando la desigualdad social en distintos sectores de la población como, por ejemplo, en los ciudadanos "con educación básica y sin discapacidad intelectual", así como en los migrantes que hablen o no la lengua mayoritaria del país al suprimir y, por tal motivo, escamotear información relevante en aras de su supuesta difusión masiva. Esto acarrea, como explica Arnoux (2015) para el caso de los manuales de estilo para escribir en Internet, pero que se puede extrapolar sin inconvenientes al caso que aquí estudiamos, un tratamiento de minorización, de estigmatización de ciertos grupos y sectores de la sociedad. La pregunta que subyace en este punto es qué tipo de ciudadanía entonces se quiere construir.

El uso del lenguaje políticamente correcto no contribuye a erradicar en absoluto la desigualdad si lo único que se hace para paliar la situación se limita a la esfera de lo retórico. En efecto, esto no provoca ninguna acción social concreta sobre la lengua. La clave para lograr la justicia social en el acceso al lenguaje reside, como se sabe, no en la regulación discursiva en ciertas esferas que se orientan a reducir y limitar la capacidad inferencial de los destinatarios sino -y principalmente- en la apuesta por extender y mejorar la educación para la ciudadanía en su conjunto. Ese gesto sí que constituiría, sin duda alguna, un acto de política lingüística al servicio de la igualdad.

\footnotetext{
10 "Este monopolio se ve con más claridad en la regulación del discurso, posiblemente el aspecto más importante y efectivo de la glotopolítica. [...] El 'poder de la palabra', la posibilidad de influir y de manipular a las personas mediante la regulación de la acción discursiva 'desde arriba', es decir, en consonancia con los intereses de la clase dominante, no es solo una metáfora, sino que se trata de una auténtica posición de poder, un apropiarse del idioma, y una posesión del idioma que fundamenta la hegemonía". La traducción es nuestra.
} 


\section{BIBLIOGRAFÍA}

ARNOUX, Elvira, N. de. La prensa escrita en manuales de retórica del siglo XIX: deslindes genéricos e ideologías lingüísticas. Olivar, en prensa.

ARNOUX, Elvira Narvaja de. El disciplinamiento de la discursividad y sus desplazamientos en los manuales de retórica del siglo XIX destinados a la educación secundaria. En: ARNOUX, Elvira Narvaja de; PAPALINI, Vanina; GUTIÉRREZ GIRALDO, Isabel (Eds.). Procesos de subjetivación y control. Una mirada crítica a los procesos de disciplinamiento. Cali: Universidad del Valle, Facultad de Ciencias de la Administración, 2018. pp. 21-52.

ARNOUX, Elvira Narvaja de. La perspectiva glotopolítica en el estudio de los instrumentos lingüísticos: aspectos teóricos y metodológicos. Matraga, $\mathrm{n}^{\circ}$ 38, 18-42, 2016.

ARNOUX, Elvira Narvaja de. Los manuales de estilo periodísticos para las versiones on line: las representaciones del lector y su incidencia en la regulación de discursos y prácticas". Circula, $\mathrm{n}^{\circ}$ 2, 138-160, 2015.

ARNOUX, Elvira Narvaja de. Los discursos sobre la nación y el lenguaje en la formación del Estado (Chile, 1842-1862). Estudio glotopolítico. Buenos Aires: Santiago Arcos, 2008.

ARNOUX, Elvira Narvaja de. Análisis del discurso. Modos de abordar materiales de archivo. Buenos Aires: Santiago Arcos, 2006.

ARNOUX, Elvira Narvaja de; DEL VALLE, José. Las representaciones ideológicas del lenguaje. Discurso glotopolítico y panhispanismo. Spanish in Context, vol. 7, $\mathrm{n}^{\circ}$ 1, 1-24, 2010.

AUROUX, Sylvain. A revolução tecnológica da gramatização. Campinas: Unicamp, 1992.

BECKER, Lidia. Lenguaje claro / llano / ciudadano y lectura fácil: ¿nuevas variedades de comunicación digital de masas más allá del español general / común / total o internacional / neutro? En: GREUßLICH, Sebastian; LEBSANFT, Franz (Eds.). El pluricentrismo de la cultura lingüística hispánica. Reflejos en los medios de comunicación masiva. Göttingen: Vandenhoeck \& Ruprecht, en prensa.

BOCHMANN, Klaus. Hexemonía lingüística e os donos da linguaxe. En Grial, vol. 55, n² 216, pp. 13-19, 2017.

CAMERON, Deborah. Verbal hygiene. Londres: Routledge, 1995.

DUCHÊNE, Alexandre; HELLER, Monica (Eds.). Language in late capitalism: pride and profit. Londres: Routledge, 2012.

HELLER, Monica; MCELHINNY, Bonnie S. Language, Capitalism, Colonialism: toward a critical history. New York: University of Toronto Press, 2017.

LARA, Luis Fernando. Temas del español contemporáneo. México: El Colegio de México, 2015.

LARA, Luis Fernando. Lenguaje ciudadano (o "Plain language" y cultura en el siglo XXI). Boletín editorial, $\mathrm{n}^{\circ}$ 124, 15-20, 2006.

LAURIA, Daniela. La política lexicográfica actual de las academias de la lengua española: el caso del Diccionario de americanismos (ASALE, 2010). Lexis, vol. XLI, n 2, 263-310, 2017.

NOGUEIRA, Sylvia. De la norma a la recomendación en manuales de estilo: el caso de Escribir en Internet de Fundéu BBVA. En: ARNOUX, Elvira Narvaja de; LAURIA, Daniela (Comps.). Lenguas y discursos en la construcción de la ciudadanía sudamericana. Gonnet: Unipe Editorial Universitaria, 2016. pp. 267-282.

ZOPPI FONTANA, Mónica. Língua oficial e políticas públicas de equidade de gênero. Línguas e Instrumentos Linguísticos, $\mathrm{n}^{\circ}$ 36, 221-246, 2015.

Artigo recebido em: out. de 2018.

Aprovado e revisado em: março de 2019.

Publicado em: dezembro de 2019. 
Para citar este texto:

LAURÍA, Daniela. Sobre el programa "Justicia en Lenguaje Claro" del Ministerio de Justicia y Derechos Humanos de la Nación (Argentina). Entremeios [Revista de Estudos do Discurso, ISSN 2179-3514, on-line, www.entremeios.inf.br], Seção Estudos, Programa de Pós-Graduação em Ciências da Linguagem (PPGCL), Universidade do Vale do Sapucaí (UNIVÁS), Pouso Alegre (MG), vol. 18, p. 43-61, jan. - jun. 2019.

DOI: http://dx.doi.org/10.20337/ISSN2179-3514revistaENTREMEIOSvol18pagina43a61 